\title{
Assessment of Quality of Life in Patients with Chronic Heart Failure in Yalgado Ouédraogo University Hospital of Ouagadougou (Burkina Faso)
}

\author{
Koudougou Jonas Kologo1,2, Georges Rosario Christian Millogo, 1,2, Anna Thiam Tall1,2, \\ Théodore Boro1, Georges Kinda ${ }^{2,3}$, Yibar Kambiré2,4, Yaya Barro', Laurent Sia1, \\ Hermann E. Adoko', Robert Natama ${ }^{1}$, Jean Baptiste Tougma ${ }^{5}$, \\ André K. Samadoulougou1,2, Patrice Zabsonré1,2 \\ ${ }^{1}$ Cardiology Department of Yalgado Ouédraogo University Hospital, Ouagadougou, Burkina Faso \\ ${ }^{2}$ University Department of Medical Science (UFR/SDS)/University Ouaga 1 Professor Joseph KI-ZERBO, Ouagadougou, \\ Burkina Faso \\ ${ }^{3}$ Medical Pediatric Department of Charles De Gaulle Pediatric University Hospital of Ouagadougou, Ouagadougou, Burkina Faso \\ ${ }^{4}$ National Hospital Blaise Compaoré of Ouagadougou, Ouagadougou, Burkina Faso \\ ${ }^{5}$ Cardiology Department of Souro Sanou University Hospital of Bobo Dioulasso, Bobo Dioulasso, Burkina Faso \\ Email: *millogo_rosa@yahoo.fr
}

How to cite this paper: Kologo, K.J., Millogo, G.R.C., Tall, A.T., Boro, T., Kinda, G., Kambiré, Y., Barro, Y., Sia, L., Adoko, H.E., Natama, R., Tougma, J.B., Samadoulougou, A.K. and Zabsonré, P. (2018) Assessment of Quality of Life in Patients with Chronic Heart Failure in Yalgado Ouédraogo University Hospital of Ouagadougou (Burkina Faso). Open Access Library Journal, 5: e4252.

https://doi.org/10.4236/oalib.1104252

Received: December 13, 2017

Accepted: January 14, 2018

Published: January 17, 2018

Copyright (๑) 2018 by authors and Open Access Library Inc.

This work is licensed under the Creative Commons Attribution International License (CC BY 4.0).

http://creativecommons.org/licenses/by/4.0/

\begin{abstract}
Objective: Our study aimed at assessing the quality of life (QoL) of patients treated for chronic heart failure (HF), and analyzing the impact of certain factors on that QoL, in the cardiology department of Yalgado Ouédraogo University Hospital of Ouagadougou. Means and Method: It was a descriptive cross-sectional study, performed over a six-month period from May to October 2016. In the study, patients with age over 18 years were included, followed up for chronic HF for at least six months in the outpatient unit, from January $1^{\text {st }}$ to December $31^{\text {st }} 2015$. The questionnaire "Minnesota Living with Heart Failure" was used to assess the QoL. Results: Two hundred and four patients were enrolled. Most of them were living in Ouagadougou (82.8\%). Sex ratio was 0.98 , and mean age was $56.06+16.37$ years. The mean overall QoL score was $17.8+16.5$. QoL was considered good in its three dimensions, in more than $70 \%$ of patients. Looking at the mean scores, the male patients, the patients living in rural and semi-urban areas, the patients with impaired left ventricular ejection fraction and those with severe or end-stage renal failure had significant QoL impairment. Multiple linear regression reported significant correlation between QoL impairment and the following factors ( $\mathrm{p}$ value $<0.05$ for all variables): marital life, number of hospitalizations for acute HF, and
\end{abstract}


NYHA functional stage. Conclusion: Marital life, number of hospitalizations for acute decompensation, and NYHA functional stage were predictive factors of QoL impairment. MLHF questionnaire should be commonly used to assess the efficiency of HF management. Self administration instead of assistance in filling the questionnaire, could insure a more objective valuation of QoL.

\section{Subject Areas}

Cardiology, Public Health

\section{Keywords}

Quality of Life, Heart Failure, Minnesota Living with Heart Failure Questionnaire

\section{Introduction}

Heart failure (HF) is a major cause of disability with significant impairment of quality of life (QoL), which is rated by the patients themselves. Due to the chronic and usually irreversible nature of HF, assessment of QoL is of great interest. According to the World Health Organization (1994), QoL is defined as the individual's perception of his position in life, in the context of culture and value system in which he has been living, in relation to his objectives, his expectations, his standards and his concerns [1]. The basic point of this definition is the notion of perception, which means that the patient's opinion is primordial.

Physiological methods of evaluation such as stress tests, have been used as replacement means to measure QoL without much reliability [2]. Direct means of measure such as the questionnaire of the University of Minnesota were developed to meet this need; this widely used questionnaire enables the assessment of the disease and treatments' effects on the QoL of patients suffering from HF [2]. Unlike the developed countries, studies on the QoL of patients suffering from HF are scarce in Africa [3] [4]. No study has been performed on this issue in Burkina Faso even though QoL has become a major concern in health sector. Taking QoL into account is a rightful wish of the medical community, to know how patients live with their disease.

Our study aimed at assessing QoL of patients suffering from chronic HF in the cardiology department of Yalgado Ouédraogo University Hospital (YOUH) of Ouagadougou.

\section{Methods}

It was a descriptive cross-sectional study performed on patients reviewed from May $1^{\text {st }}$ to October $31^{\text {st }} 2015$, on outpatient basis in the cardiology department of YOUH of Ouagadougou. Patients above 18 years, with chronic HF and under medical treatment for at least six months, were included in the study. We excluded the patients with acute cardiac decompensation requiring hospitalization; 
those with unstable angina or who had myocardial infarction within the last six months; those on treatment for cancer; those on hemodialysis, and those with cognitive disorders.

QoL has been assessed through the "Minnesota Living with Heart Failure" (MLHF) questionnaire [2]. This questionnaire has been developed to explore how HF and its treatments can affect the physical, emotional, social and mental dimensions of a patient's life over the past four weeks. Each of the 21 items of the questionnaire was marked by the patient on a Likert type score scale, from zero to five according to the increasing degree of disturbance on lifestyle. The sum of the answers to the 21 items, ranging from zero to 105 enabled the assessment of the patient's overall QoL. Eight items with a total score ranging from zero to 40 enabled the assessment of the physical dimension of the patient's QoL, while the sum of the answers to five other items (total from zero to 25) enabled the assessment of the emotional dimension of the patient's QoL. The higher the cores, the more impaired the patient's QoL; the lower the scores, the better the QoL.

Table 1 summarizes the content and interpretation of the MLHF questionnaire

Table 1. Summary of the content and interpretation of the MLHF questionnaire [16].

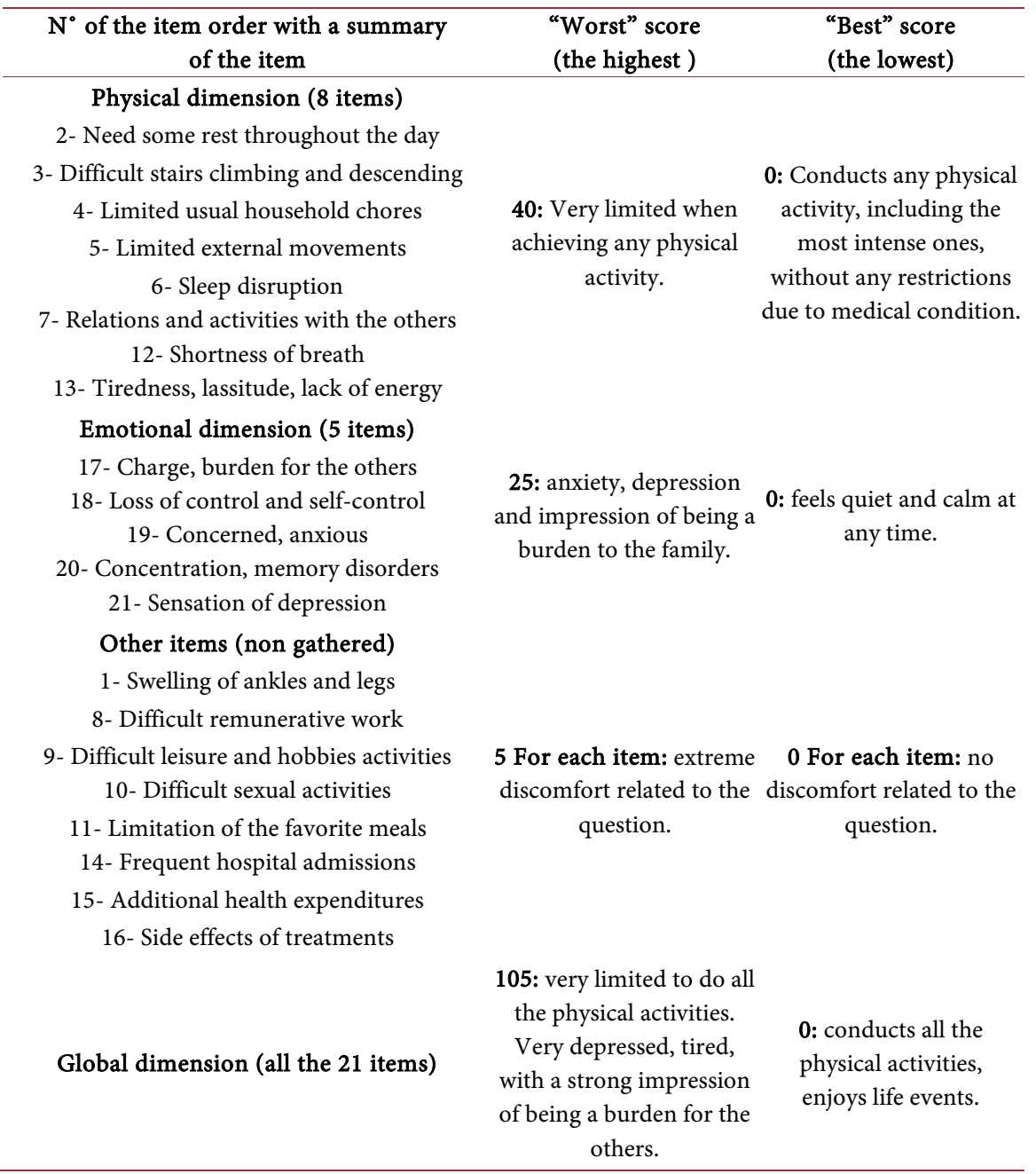


[5] [6]. Various variables were collected to describe the study population and identify the determining elements of QoL in chronic HF. Socio-demo- graphic variables included age, gender, marital status, profession, geographic origin, educational and socio-economic level. Variables assessing the disease severity included HF duration, number of hospital admissions for acute decompensation, functional stage of dyspnea according to the New York Heart Association (NYHA), systolic blood pressure (SBP), creatinine clearance, left ventricular ejection fraction (LVEF), systolic pulmonary arterial pressure (SPAP). The latest biological and cardiac echography parameters were analyzed. Impairment of the left ventricular systolic function was defined by a LVEF $<40 \%$ [5], while pulmonary artery hypertension meant a SPAP $>40 \mathrm{mmHg}$ [7].

Patients enrolled in the study after giving their informed consent, were invited at the outpatient unit for data collection. Confidentiality and anonymity were respected. The MLHF questionnaire was self-administered for about 10 minutes before other variables were collected. The investigator translated as faithfully as possible the questions, in the patient's native language when this one could not speak French fluently. The unanswered questions were systematically marked zero. To make interpretation and comparison easier, the three scores (overall, physical and emotional) were each scaled from 0 to 100 by a rule of three, so that 0 corresponds to the best QoL and 100 to the worst QoL. The QoL was deemed good for a score between [0 - 25], slightly impaired for a score between [26 - 50], moderately impaired for a score between [51 - 75] and severely impaired for a score between [76 - 100].

Data were analyzed through the 3.5 version of the software Epi info. The $\mathrm{X}^{2}$ test was used to compare qualitative variables while the quantitative ones were compared through the Student t-test or variance analysis (ANOVA). The correlation of the QoL scores with various factors was analyzed through multiple linear regression. The tests were statistically significant for a value of $\mathrm{p}<0.05$. Data confidentiality was considering when collecting data and data anonymity has been respected. The local ethical committee was approved this study.

\section{Results}

204 patients with chronic HF were included in the study. Table 2 shows the socio-demographical, clinical, para clinical and therapeutic characteristics of the patients.

56 patients filled-up the MLHF questionnaire by themselves (27.5\%); 148 patients $(72.5 \%)$ were provided support when filling-up the form (questions explanations or full translation of the questionnaire in one native language). The mean overall score of QoL for the 204 patients was $17.8 \pm 16.5$ over 105, with extremes of zero and 72 . The means physical and emotional sub-scores were respectively $6.7 \pm 8.6$ over 40 (extremes of zero and 35) and $5.4 \pm 5.1$ over 25 (extremes of zero and 23). The issues that less affected patients' lifestyle (zero point) during the past four weeks were question 1 related to ankles swelling, question 6 
Table 2. Socio-demographic, clinical, paraclinical and therapeutic characteristics of 204 patients.

\begin{tabular}{|c|c|c|}
\hline Features & $\begin{array}{l}\text { Average } \pm \text { standard } \\
\text { deviation }\end{array}$ & $\mathrm{N}(\%)$ \\
\hline Age & $56 \pm 16$ & \\
\hline Female & & $103(50.5)$ \\
\hline Living in urban area & & $169(82.8)$ \\
\hline Living as a couple & & $148(72.5)$ \\
\hline \multicolumn{3}{|l|}{ Educational level } \\
\hline Not enrolled at school & & $95(46.6)$ \\
\hline Primary school level & & $46(22.5)$ \\
\hline Low socio-economical level & & $102(50)$ \\
\hline \multicolumn{3}{|l|}{ Heart failure duration so far } \\
\hline Less than one year & & $28(13.7)$ \\
\hline Over five years & & $59(28.9)$ \\
\hline $\begin{array}{l}\text { Several hospital admissions because of acute } \\
\text { decompensation }\end{array}$ & & $53(26)$ \\
\hline \multicolumn{3}{|l|}{ Functional class of NYHA dyspnea } \\
\hline Phase I & & $121(59.3)$ \\
\hline Phase II & & $71(34.8)$ \\
\hline Phase III/IV & & $12(5.9)$ \\
\hline Systolic blood pressure Tension $<100 \mathrm{mmHg}$ & & $20(9.8 \%)$ \\
\hline Creatinine clearance & $52.3 \pm 15.4 \mathrm{ml} / \mathrm{min}$ & \\
\hline End-stage or severe renal failure & & $18(8.8)$ \\
\hline Presence of atrial fibrillation & & $32(15.7)$ \\
\hline Left ventricular ejection fraction (LVEF) & $47.8 \% \pm 14.7 \%$ & \\
\hline Impairment of the LVEF & & $82(40.2)$ \\
\hline Pulmonary arterial blood pressure & & $83(40.7)$ \\
\hline \multicolumn{3}{|l|}{ Medical therapy } \\
\hline Furosemide + IEC/ARA II + spironolactone & & $114(55.9 \%)$ \\
\hline \multicolumn{3}{|l|}{ Furosemide + IEC/ARA II + spironolactone } \\
\hline + beta-blocker & & $26(12.7 \%)$ \\
\hline \multicolumn{3}{|l|}{ Furosemide + IEC/ARA II + spironolactone } \\
\hline+ digitalis therapy & & $17(8.3 \%)$ \\
\hline
\end{tabular}

NYHA: New York Heart Association; IEC/ARAII: inhibitors of the antagonist or converting enzyme of the receptors of angiotensin II.

related to sleep disorders and question 14 related to frequent hospital admissions. The issues that mostly disturbed patients' lifestyle (five points) were question 10 related to difficult sexual activity, question 15 related to additional expenditures and question 19 related to anxiety and various worries. QoL was deemed good in its overall, physical and emotional dimensions respectively in $77.9 \%, 78.4 \%$ and $70.6 \%$ of patients. The physical dimension was severely impaired among $2.5 \%$ of patients while $2 \%$ had severe impairment in the emotional 
dimension. No patient had severe impairment of QoL in its overall dimension.

Table 3 compares QoL scores according to the presence or absence of some socio-demographic, clinical and para clinical factors. Table 4 shows the correlation between the various dimensions of QoL and the socio-demographic, clinical and para clinical factors, as well as the MLHF questionnaire conditions of administration.

The predictive factors of an impaired QoL among the patients with HF were the following: marital life; several hospital admissions for acute decompensation; NYHA advanced stage of dyspnea. Patients who were provided help when filling-up the form had a better quality of life compared to those who filled it by their own.

\section{Discussion}

HF affects QoL of patients in different ways: by weakening physical performances due to asthenia and dyspnea; by giving way to mood disorders due to

Table 3. Comparisons of the averages of the scores of the quality of life according to the presence of certain socio-demographical, clinical and paraclinical factors.

\begin{tabular}{|c|c|c|c|}
\hline \multirow[b]{2}{*}{ Factors } & \multicolumn{3}{|c|}{ Average scores of the quality of life } \\
\hline & $\begin{array}{l}\text { Physical } \\
\text { dimension }\end{array}$ & $\begin{array}{l}\text { Emotional } \\
\text { dimension }\end{array}$ & Global dimension \\
\hline Men & 19.3 & 22.7 & $19.2^{*}$ \\
\hline Women & 14.3 & 20.7 & 4.9 \\
\hline Living in union & $18.6^{*}$ & 22.2 & $18.3^{*}$ \\
\hline Living alone & 11.7 & 20.1 & 13.4 \\
\hline Rural or semi urban area & $24.1^{*}$ & $28.5^{*}$ & $22.4^{*}$ \\
\hline Urban area & 15.2 & 20.4 & 15.9 \\
\hline \multicolumn{4}{|l|}{ NYHA dyspnea } \\
\hline Phase I & $8.3^{\star}$ & $17^{*}$ & $11.8^{*}$ \\
\hline Phase II & 24.9 & 27 & 22.4 \\
\hline Phase III & 42.2 & 32 & 30.9 \\
\hline Phase IV & 84.3 & 58.7 & 56.3 \\
\hline $\mathrm{SBP}<100 \mathrm{mmHg}$ & $26^{*}$ & $33^{*}$ & $26^{*}$ \\
\hline $\mathrm{SBP}>100 \mathrm{mmHg}$ & 16 & 20 & 16 \\
\hline Severe or end-stage RF & 22.7 & $33^{*}$ & 23.3 \\
\hline Normal renal function & 16.2 & 20.7 & 16.4 \\
\hline Impaired LVEF & $23.1^{*}$ & 24.4 & $21.8^{*}$ \\
\hline Normal LVEF & 12.4 & 19.9 & 13.8 \\
\hline Pulmonary artery blood pressure & 19.2 & 24.1 & $19^{*}$ \\
\hline Normal PAPS & 13 & 19.1 & 14.1 \\
\hline Self-administration of the questionnaire & $23.3^{*}$ & 24.9 & $22.3^{\star}$ \\
\hline Help received when filling the questionnaire & 14.3 & 20.6 & 15 \\
\hline
\end{tabular}

*: p < 0.05; NYHA: New York Heart Association; RF: Renal Failure; SBP: Systolic Blood Pressure; LVEF: Left Ventricle Ejection Fraction; PAPS: Systolic Pulmonary Artery pressure. 
Table 4. Correlations between the quality of life and the socio-demographic, clinical, paraclinical factors as well as the conditions to administer the MLHF questionnaire.

\begin{tabular}{|c|c|c|c|}
\hline \multirow{2}{*}{ Clinical and Para clinical factors } & \multicolumn{3}{|c|}{ Correlation coefficient } \\
\hline & Global score & Physical score & Emotional score \\
\hline Age & 0.03 & -0.12 & -0.07 \\
\hline Sex & 3.7 & -0.16 & 0.8 \\
\hline Marital status & 5 & $10.5^{\mathrm{t}}$ & 2.3 \\
\hline Geographical origin & 0.3 & -0.21 & -2.6 \\
\hline Socio-economic level & -7.6 & -9.2 & 5.2 \\
\hline HF age & -1.9 & -1.9 & -2.3 \\
\hline Educational level & -4.5 & -4.2 & -2.2 \\
\hline Number of hospital admissions due to HF & $2.8^{*}$ & $3.8^{*}$ & 0.2 \\
\hline NYHA phase of dyspnea & $12.4^{\mathbf{T}}$ & $21.8^{\mathrm{T}}$ & $12.6^{\mathrm{T}}$ \\
\hline Systolic blood pressure & -0.09 & -0.11 & -0.09 \\
\hline Creatinine clearance & 0.01 & 0.01 & 0.01 \\
\hline LVEF & 0.11 & 0.16 & 0.22 \\
\hline SPAP & 0.002 & -0.05 & 0.07 \\
\hline $\begin{array}{l}\text { Help received when filling-up the } \\
\text { questionnaire }\end{array}$ & $-11^{\mathbf{t}}$ & $-14.6^{\mathbf{T}}$ & -7.8 \\
\hline
\end{tabular}

reduced autonomy, changes related to lifestyle and financial burden imposed by the medical treatment. Several studies have highlighted the impairment of QoL of patients with HF which is influenced by various factors [4] [6] [8] [9] [10] [11]. The mean scores of QoL found in this study were largely below those reported by N'Cho-Mottoh et al. in Côte d'Ivoire [4] and by the western authors [2] [6] [12] [13]. This means that our patients had a better QoL on the overall, physical and emotional dimensions. This is due to the fact that patients of our study were enrolled in outpatient basis and were clinically stable, compared to foreign studies where the questionnaire was administered to hospitalized patients usually experiencing acute decompensation. The emotional dimension was the most impaired (score of 21.8 over 100 vs 16.7 over 100 for the physical dimension, and 17.2 over 100 for the overall dimension). This shows the mental burden HF exerts on the patient's daily life in a context of poverty with permanent anxiety due to quest of financial means to afford treatment. In the occidental series [2] [6] [9] [12] [13], QoL was most impaired in its physical dimension; in fact their patients seem to be emotional more stable as they live in a more comfortable socio-medical environment.

This study has shown that marital life, several hospital admissions due to acute decompensation and NYHA advanced stage of dyspnea were predictive factors of bad QoL. However, providing help to fill-up the MLHF questionnaire 
was a predictive factor of good quality of life. Interaction of the investigator when helping the patient to fill-up the questionnaire has probably hindered the choice of answers. Patients may not express their real discomfort, in order not to disappoint the doctor by giving the impression of treatment inefficiency. However, when the questionnaire was self-administered, answers to the questions were given without any complex as confidentiality was better; the patient having not to discuss about any question with the investigator. In our study marital life was a predictive factor of bad QoL, whilst foreign authors did not found any relationship between marital status of patients and their QoL [4] [6] [9]. In our context, additional expenses generated by family responsibilities in marital life could have contributed to impair the QoL. Like our study, several authors reported a significantly impaired QoL particularly in the physical and overall dimensions, sometimes in the emotional dimension [4] [13] [14] [15] among patients who had several hospital admissions. The number of hospital admissions of patients suffering from chronic affections is usually correlated to the gradual deterioration of their health status. Obviously, the severe the pathology, the more impaired the QoL. Most of the studies like ours, found a significant correlation between the NYHA stage of dyspnea and impairment of the QoL, particularly in its physical and overall dimensions [4] [6] [16] [17] [18]. This association shows the direct impact of reduced functional capacities on the patient's physical performances. The severity of dyspnea according to NYHA classification is likely to contribute to the impairment of the emotional QoL as reported in our study. According to some researchers, hyperactivity of the sympathetic nervous system in response to $\mathrm{HF}$, could result into mental depression, likely to disturb the physical and psychological QoL [19]. Moreover, functional capacity reduction of initially active patients could affect their mind and generate a loss of self-confidence.

Age was not significantly linked to a bad QoL in our study. Heo et al. in the USA [20] found a more impaired QoL among older patients compared to younger ones. According to them, advanced age itself is a major cardiovascular risk factor and a favorable ground for the association of co-morbidities. However, several studies have noted a significantly impaired quality of life among younger patients suffering from HF [4] [9] [11] [16] [18], sustaining the assumption whereby elderly could better bear reduction of physical activities, as they realize age related co-morbidities and gradual degradation of their general health condition.

In our study, QoL was significantly more impaired in men in its overall dimension. However, most studies which used the MLHF questionnaire reported the opposite [6] [11] [16] [21]. These gender-related differences could derive from the responsibilities assigned to each partner of a couple, based on the system of value peculiar to the society they've been living in.

QoL in all dimensions was more significantly impaired among patients from rural or semi urban area compare to those living in Ouagadougou. Challenges in 
accessibility to a specialist and therapeutic discontinuations due to drugs unavailability in remote areas could explain this situation. In our study, socioeconomic and educational levels did not significantly influenced QoL. Barbareschi in the Netherlands [22], Clark in the USA [23] and Lee in Hong Kong [24] demonstrated that QoL was significantly better among HF patients with high socio-economic and/or educational level. According to these authors, deprived patients and those with low educational level are more exposed and more vulnerable to stressful situations, are less compliant to treatments and often have tenuous health condition. In our context, these effects are probably counterbalanced by the great socio-familial support provided to our patients.

Severe or end-stage renal failure in our patients with HF, was associated to a poor QoL on the emotional dimension. Indeed, some studies reported that the presence of co-morbidities significantly impaired the QoL of HF patients [6] [13] [16], probably due to the additive noxious effects of combined chronic pathologies.

We observed significantly impaired QoL in all three dimensions, among patients with SBP lower than $100 \mathrm{mmHg}$. Lewis in the USA [25] and Rodriguez in Spain [13] also found high scores of QoL in case of low SBP, but with no significant difference with patients having normal blood pressure. Decreased blood pressure is sometimes due to the effects of vasodilator medications; but it's usually the translation of a proportional decrease of left ventricular systolic function, resulting in poor tissue and organ perfusion, likely to explain the impaired QoL.

Our study like that of Kitzman et al. in the USA [26], reported that QoL in its physical and overall dimensions was significantly impaired among patients with reduced LVEF. Most studies did not find any correlation between LVEF and QoL impairment, assessed by either generics or HF specific questionnaires [25] [27] [28] [29]. Those authors remind that the value of LVEF is not necessarily a predictor of HF severity, as clinical manifestations are the same in case of both HF with preserved or reduced ejection fraction. Our study analyzed the results of the patient's latest cardiac echography and most of those who had LVEF above $40 \%$ did not suffer from HF with preserved ejection fraction; their ejection fraction was initially impaired then later got improved in the course of treatment, to surpass the threshold of $40 \%$ at the time of data collection. Increment of ejection fraction went in line with the improvement of clinical symptomatology, resulting thereby into a better QoL among these patients.

Patients with high SPAP had more impaired QoL compared to those with normal SPAP; the difference was statistically significant only for the overall dimension. Indeed, high SPAP most often is the translation of an advanced stage of HF with poor prognosis, likely to explain the impaired QoL experienced by these patients.

Some studies found significant improvement of MLHF questionnaire scores under HF-specific beta-blockers [3] [30] [31]. However, Wilson et al. [32], the 
RESOLVD study [33] as well as our study did not find any significant change in the QoL of patients under beta-blockers. These differences could be related to the type of studies and the type of beta-blockers that were used. Anyway, the effects of HF-specific beta-blockers on the reduction of morbi-mortality are nowadays unquestionable [34].

\section{Conclusions}

Our study reported that more than $70 \%$ of patients with HF in the cardiology department of YOUH of Ouagadougou had a good QoL. The emotional dimension of QoL was the most impaired one in our population mainly made up of poor people, despite the renowned African solidarity. Male gender, marital life, living in semi-urban or rural area, multiple hospital admissions for decompensated HF, advanced stage of dyspnea, impaired LVEF, high SPAP, impaired kidney function, were significantly associated to a poor QoL.

Multiple regression analysis noticed that marital life, multiple hospital admissions for decompensated HF and NYHA advanced stage of dyspnea were the only predictors of impaired QoL in one or the other dimensions. Conditions of questionnaire administration regarding our context of low education level, do not provide a faithful appraisal of patients QoL. Indeed, the principle of confidentiality devoted to self-administration of the questionnaire and aiming at ensuring objective answers could not be appropriately applied, as help was often required to fill up the questionnaire. Health workers are urged to recognize along with the physical symptoms of HF, the warning signs of mental disorders induced by the chronicity of the disease. In addition to the standard treatments, therapeutic education sessions and psychological support could help improve patients QoL.

\section{References}

[1] WHOQOL Group (1994) Development of the WHOQOL: Rationale and Current Status. International Journal of Mental Health, 23, 24-56. https://doi.org/10.1080/00207411.1994.11449286

[2] Rector, T.S. and Cohn, J.N. (1992) Assessment of Patient Outcome with the Minnesota Living with Heart Failure questionnaire: Reliability and Validity during a Randomized, Double-Blind, Placebo-Controlled Trial of Pimobendan. American Heart Journal, 124, 1017-1025. https://doi.org/10.1016/0002-8703(92)90986-6

[3] Maazoun, Y., Abid, L., Krichène, S., et al. (2013) Impact des bêtabloquants sur les paramètres fonctionnels de l'insuffisance cardiaque stable. Cardiologie Tunisienne, 9, 34-41.

[4] N'cho-Mottoh, M.P.B., Coulibaly, I., Yayehd, K., Boka, B., Bamba-Kamagate, D. and Sow-Touré, M. (2015) Facteurs prédictifs de la qualité de vie de l'insuffisant cardiaque noir africain. Medecine d'Afrique Noire, 62, 541-546.

[5] Ponikowski, P., Voors, A.A., Anker, S.D., Bueno, H., Cleland, J.G.F., Coats, A.J.S., Falk, V., González-Juanatey, J.R., Harjola, V.-P., Jankowska, E.A., Jessup, M., Linde, C., Nihoyannopoulos, P., Parissis, J.T., Pieske, B., Riley, J.P., Rosano, G.M.C., Ruilope, L.M., Ruschitzka, F., Rutten, F.H., van der Meer, P. and Authors/Task Force 
Members (2016) 2016 ESC Guidelines for the Diagnosis and Treatment of Acute and Chronic Heart Failure: The Task Force for the Diagnosis and Treatment of Acute and Chronic Heart Failure of the European Society of Cardiology (ESC) Developed with the Special Contribution of the Heart Failure Association (HFA) of the ESC. European Heart Journal, 37, 2129-2200.

https://doi.org/10.1093/eurheartj/ehw128

[6] Hoekstra, T., Jaarsma, T., van Veldhuisen, D.J., Hillege, H.L., Sanderman, R. and Lesman-Leegte, I. (2013) Quality of Life and Survival in Patients with Heart Failure. European Journal of Heart Failure, 15, 94-102.

https://doi.org/10.1093/eurjhf/hfs148

[7] Mukerjee, D., St George, D., Knight, C., Davar, J., Wells, A.U., Du Bois, R.M., Black, C.M. and Coghlan, J.G. (2004) Echocardiography and Pulmonary Function as Screening Tests for Pulmonary Arterial Hypertension in Systemic Sclerosis. Rheumatology, 43, 461-466. https://doi.org/10.1093/rheumatology/keh067

[8] Chryssanthopoulos, S.N., Dritsas, A. and Cokkinos, D.V. (2005) Activity Questionnaires; A Useful Tool in Accessing Heart Failure Patients. International Journal of Cardiology, 105, 294-299. https://doi.org/10.1016/j.ijcard.2004.12.046

[9] Hwang, S.-L., Liao, W.-C. and Huang, T.-Y. (2014) Predictors of Quality of Life in Patients with Heart Failure. Japan Journal of Nursing Science, 11, 290-298. https://doi.org/10.1111/jjns.12034

[10] Naveiro-Rilo, J.C., Diez-Juárez, D.M., Romero Blanco, A., Rebollo-Gutiérrez, F., Rodríguez-Martínez, A. and Rodríguez-García, M.A. (2010) Validation of the Minnesota Living with Heart Failure Questionnaire in Primary Care. Revista Española de Cardiología, 63, 1419-1427. https://doi.org/10.1016/S0300-8932(10)70268-2

[11] Nesbitt, T., Doctorvaladan, S., Southard, J.A., et al. (2014) Correlates of Quality of Life in Rural Patients with Heart Failure. Circulation: Heart Failure, 7, 882-887. https://doi.org/10.1161/CIRCHEARTFAILURE.113.000577

[12] Hoekstra, T., Lesman-Leegte, I., van Veldhuisen, D.J., Sanderman, R. and Jaarsma, T. (2011) Quality of Life Is Impaired Similarly in Heart Failure Patients with Preserved and Reduced Ejection Fraction. European Journal of Heart Failure, 13, 1013-1018. https://doi.org/10.1093/eurjhf/hfr072

[13] Rodríguez-Artalejo, F., Guallar-Castillón, P., Pascual, C.R., et al. (2005) Health-Related Quality of Life as a Predictor of Hospital Readmission and Death among Patients with Heart Failure. Archives of Internal Medicine, 165, 1274-1279. https://doi.org/10.1001/archinte.165.11.1274

[14] Konstam, V., Salem, D., Pouleur, H., et al. (1996) Studies of Left Ventricular Dysfunction Investigators. Baseline Quality of Life as a Predictor of Mortality and Hospitalization in 5,025 Patients with Congestive Heart Failure: SOLVD Investigations. American Journal of Cardiology, 78, 890-895.

https://doi.org/10.1016/S0002-9149(96)00463-8

[15] Stull, D., Clough, L. and Van Dussen, D. (2001) Self-Report Quality of Life as a Predictor of Hospitalization for Patients with LV Dysfunction: A Life Course Approach. Research in Nursing \& Health, 24, 460-469. https://doi.org/10.1002/nur.10006

[16] Gott, M., Barnes, S., Parker, C., et al. (2006) Predictors of the Quality of Life of Older People with Heart Failure Recruited from Primary Care. Age Ageing, 35, 172-177. https://doi.org/10.1093/ageing/afj040

[17] Hobbs, F.D.R., Kenkre, J.E., Roalfe, A.K., Davis, R.C., Hare, R. and Davies, M.K. (2002) Impact of Heart Failure and Left Ventricular Systolic Dysfunction on Quality 
of Life: A Cross-Sectional Study Comparing Common Chronic Cardiac and Medical Disorders and a Representative Adult Population. European Heart Journal, 23, 1867-1876. https://doi.org/10.1053/euhj.2002.3255

[18] Riedinger, M.S., Dracup, K.A. and Brecht, M.L. (2000) Predictors of Quality of Life in Women with Heart Failure. SOLVD Investigators. Studies of Left Ventricular Dysfunction. The Journal of Heart and Lung Transplantation: The Official Publication of the International Society for Heart Transplantation, 19, 598-608. https://doi.org/10.1016/S1053-2498(00)00117-0

[19] Dekker, R., Peden, A., Lennie, T., Schooler, M. and Moser, D. (2009) Living with Depressive Symptoms: Patients with Heart Failure. American Journal of Critical Care, 18, 310-319. https://doi.org/10.4037/ajcc2009672

[20] Heo, S., Lennie, T.A., Okoli, C. and Moser, D.K. (2009) Quality of Life in Patients with Heart Failure: Ask the Patients. Heart \& Lung. The Journal of Acute and Critical Care, 38, 100-108. https://doi.org/10.1016/j.hrtlng.2008.04.002

[21] Hou, N., Chui, M.A., Eckert, G.J., Oldridge, N.B., Murray, M.D. and Bennett, S.J. (2004) Relationship of Age and Sex to Health-Related Quality of Life in Patients with Heart Failure. American Journal of Critical Care, 13, 153-161.

[22] Barbareschi, G., Sanderman, R., Lesman-Leegte, I., Veldhuisen, D. and Jaarsma, T. (2011) Educational Level and the Quality of Life of Heart Failure Patients : A Longitudinal Study. Journal of Cardiac Failure, 17, 47-53. https://doi.org/10.1016/j.cardfail.2010.08.005

[23] Clark, D., Tu, W., Weiner, M. and Murray, M. (2003) Correlates of Health-Related Quality of Life among Lower-Income, Urban Adults with Congestive Heart Failure. Herat Lung, No. 32, 391-401.

[24] Lee, D., Yu, D., Woo, J. and Thompson, D. (2005) Health-Related Quality of Life in Patients with Congestive Heart Failure. European Journal of Heart Failure, 7, 419-422. https://doi.org/10.1016/j.ejheart.2004.08.004

[25] Lewis, E.F., Lamas, G.A., O’Meara, E., et al. (2007) Characterization of Health-Related Quality of Life in Heart Failure Patients with Preserved versus Low Ejection Fraction in CHARM. European Journal of Heart Failure, 9, 83-91. https://doi.org/10.1016/j.ejheart.2006.10.012

[26] Kitzman, D.W., Little, W.C., Brubaker, P.H., et al. (2002) Pathophysiological Characterization of Isolated Diastolic Heart Failure in Comparison to Systolic Heart Failure. JAMA, 288, 2144-2150. https://doi.org/10.1001/jama.288.17.2144

[27] Austin, B.A., Wang, Y., Smith, G.L., Vaccarine, V., Krumholz, H.M. and McNamara, R.L. (2008) Systolic Function as a Predictor of Mortality and Quality of Life in Long-Term Survivors with Heart Failure. Clinical Cardiology, 31, 119-124. https://doi.org/10.1002/clc.20118

[28] Jaarsma, T., Halfens, R., Abu-Saad, H., Dracup, K., Stappers, J. and Van Ree, J. (1999) Quality of Life in Older Patients with Systolic and Diastolic Heart Failure. European Journal of Heart Failure, 1, 151-160. https://doi.org/10.1016/S1388-9842(99)00007-0

[29] O’Mahony, M., Sim, M., Ho, S., Steward, J., Buchalter, M. and Burr, M. (2003) Diastolic Heart Failure in Older People. Age Ageing, 32, 519-524. https://doi.org/10.1093/ageing/afg090

[30] Lainscaka, M., Keberb, I. and Ankerc, S. (2006) Body Composition Changes in Patients with Systolic Heart Failure Treated with Beta Blockers: A Pilot Study. International Journal of Cardiology, 106, 345-348.

[31] Sizova, J., Naimann, J. and Morozova, T. (2008) Increased Activity of Endothelin-1 
in Chronic Heart Failure: The Potentials of Therapy with Beta-Blocker Nebivolol. European Journal of Heart Failure, 1, 165.

[32] Wison, S., Colucci, W., Packer, M., et al. (1996) Carvedilol Inhibits Clinical Progression in Patients with Mild Symptoms of Heart Failure. American Heart Association, 94, 2800-2806.

[33] The RESOLVD Investigators (2000) Effects of Metoprolol CR in Patients with Ischemic and Dilated Cardiomyopathy: The Randomized Evaluation of Strategies for Left Ventricular Dysfunction Pilot Study. Circulation, 101, 378-384. https://doi.org/10.1161/01.CIR.101.4.378

[34] Cohen-Solal, A., Bouvier, E. and Bourgoin, P. (2002) Bêtabloquants et insuffisance cardiaque. Réanimation, 11, 117-124.

https://doi.org/10.1016/S1624-0693(02)00218-9 